\title{
Integrating STI and MCH/FP Services
}

Population Council

Follow this and additional works at: https://knowledgecommons.popcouncil.org/departments_sbsr-rh

Part of the Demography, Population, and Ecology Commons, Family, Life Course, and Society Commons, International Public Health Commons, and the Women's Health Commons How does access to this work benefit you? Let us know!

\section{Recommended Citation}

"Integrating STI and MCH/FP Services," Africa OR/TA Programme Brief. Nairobi: Population Council, 1999. 
The integration of STI and HIV/AIDS information and services into existing $\mathrm{MCH} / \mathrm{FP}$ programs has been strongly supported in recent years, following recommendations from the 1994 Cairo ICPD. Moreover, it is now widely accepted that early detection and management of STIs can reduce the incidence of HIV infection. Thus there are powerful incentives to increase efforts to broaden the capacity of MCH/FP programs to provide STI prevention and management information and services for their clients, both as a comprehensive reproductive health service and as a preventive measure for reducing the transmission of HIV.

The Africa OR/TA Project 11, in collaboration with several agencies in the region, undertook a number of OR studies to assess the preparedness of programs to provide STI, HIV/AIDS and MCH/FP services using an integrated approach. These diagnostic studies were then followed by intervention studies to test ways of improving the existing approaches to implementing integrated services as shown below.

\section{ACTIVITIES UNDER THE AFRICA OR\TA PROJECT II}

\begin{tabular}{|c|c|}
\hline Activity Type & Location \\
\hline $\begin{array}{l}\text { Situation Analysis studies of integration } \\
\text { at clinics of STMHIV information and } \\
\text { services in national MCHIFP programs }\end{array}$ & $\begin{array}{l}\text { Botswana } \\
\text { Ghana } \\
\text { Kenya } \\
\text { TanzanialMbeya region } \\
\text { Zambia } \\
\text { Zimbabwe }\end{array}$ \\
\hline $\begin{array}{l}\text { Case studies of programs providing } \\
\text { MCHIFP, STI and HIV AIDS }\end{array}$ & $\begin{array}{l}\text { Mkomani Clinic Society, Mombasa, Kenya } \\
\text { Botswana Population Assistance Project (BOTSPA), } \\
\text { Botswana } \\
\text { Nakuru Municipal Council clinics, Kenya } \\
\text { Family Life Education Program, Busoga diocese, Uganda }\end{array}$ \\
\hline $\begin{array}{l}\text { Assessments of integration of STAHIV } \\
\text { information and services in community- } \\
\text { based programs }\end{array}$ & $\begin{array}{l}\text { Kenya (seven CBD programs) } \\
\text { Community Health and Family Planning Project, Navrongo, } \\
\text { Ghana } \\
\text { Community-Based Reproductive Health Services, Bazega, } \\
\text { Burkina Faso }\end{array}$ \\
\hline $\begin{array}{l}\text { Qualitative studies of perceptions } \\
\text { towards RTls and health-seeking } \\
\text { behavior }\end{array}$ & $\begin{array}{l}\text { Navrongo, Ghana } \\
\text { Bazega, Burkina Faso }\end{array}$ \\
\hline $\begin{array}{l}\text { Measuring the prevalence of RTls } \\
\text { among MCHIFP clients }\end{array}$ & $\begin{array}{l}\text { Nakuru Municipal Council clinics, Kenya } \\
\text { Zimbabwe national Family Planning Council clinics, } \\
\text { Zimbabwe }\end{array}$ \\
\hline $\begin{array}{l}\text { Evaluating the effectiveness of STI } \\
\text { syndromic management among } \\
\text { MCHIFP clients, and testing strategies } \\
\text { to improve this strategy }\end{array}$ & $\begin{array}{l}\text { Nakuru Municipal Council clinics, Kenya } \\
\text { Zimbabwe National Family Planning Council clinics, } \\
\text { Zimbabwe }\end{array}$ \\
\hline $\begin{array}{l}\text { Assessment of resource utilization and } \\
\text { cost-effectiveness of integrated } \\
\text { programs }\end{array}$ & $\begin{array}{l}\text { Nakuru Municipal Council clinics, Kenya } \\
\text { Zimbabwe National Family Planning Council clinics, } \\
\text { Zimbabwe }\end{array}$ \\
\hline
\end{tabular}




\section{Is there a need to offer RTIIHIV information and}

treatment services to women attending MCHIFP clinics?

OR studies conducted in Nakuru, Kenya and Harare and Bulawayo in Zimbabwe show that more than half of women attending clinics for family planning or antenatal services have a reproductive tract infection (RTI). Among these women, non-sexually transmitted infections (i.e. Candidiasis and Bacterial Vaginosis) are much more prevalent than sexually transmitted infections (STIs) (Gonorrhea, Chiamydia and Trichomoniasis).

\section{Prevalence of reproductive Tract Infections among family planning and antenatal clients in Kenya and Zimbabwe}

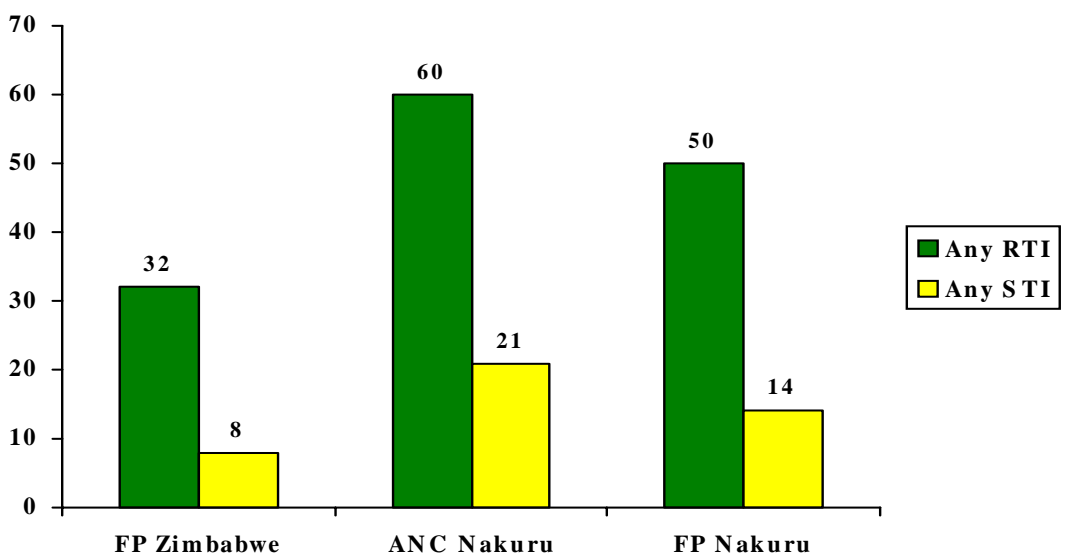

Because of their more serious effects on women's and infant health, most efforts to integrate RTI detection and treatment services have focused on sexually transmitted infections. However, these data suggest that programs aimed at improving women's reproductive health should also consider of detecting and treating non-sexually transmitted RTIs, given their widespread prevalence and the inconvenience and suffering they can cause many women. Moreover, recent linking Bacterial Vaginosis with be increased likelihood of sexual transmission of HIV, and the difficulty in distinguishing between this and other vaginal infections, suggests that program managers may need to consider vaginitis as being as important to detect and treat as the sexually transmitted Decisions on whether to integrate STI and MCHUFP services that are based on the prevalence of STIs alone may deny access to care for the large number of women with non-sexually transmitted infections. Given the emerging information that bacterial vaginosis may be associated with pelvic inflammatory disease and increased risk for HIV infection, greater attention may need to be paid to managing vaginitis infections.

Knowledge about signs, symptoms, risk factors and ways of preventing sexually transmitted infections is poor among women attending MCH/FP clinics. Less than one-fifth of clients attending $\mathrm{MCH} / \mathrm{FP}$ clinics were aware that HIV infection could be transmitted through blood transfusion, and from mother to baby. Nearly half of these women did not consider condom use an effective protection against STIs and HIV/AIDS. 
In rural communities of northern Ghana, both men and women have many beliefs concerning the cause of STIs. In addition to having sex with multiple partners and infidelity, God's will, lack of hygiene, insect

bites and inadequate or poor diets are also cited as possible causes. Because of their perceptions of the causes of STIs, for many individuals the first choice of treatment is the traditional healer. It is only when the traditional remedies have failed that they seek medical help from health facilities.

\section{Are STI andlor HIVIAIDS services currently provided at MCHIFP clinics?}

Data from Situation Analysis studies in the region show that many $\mathrm{MCH} / \mathrm{FP}$ programs in the region are already providing STI and/or HIV/AIDS information and services using an integrated approach, albeit to varying degrees. For

\section{Major components of integration strategies used by MCHVF clinic-based}

programs

- STI cases finding diagnosis, and treatment among family planning clients and to a lesser extent antenatal clients attending MCHNP clinics

- Communication of messages to clients about prevention of STIs and HIV transmission and good health seeking behaviour

- Screening and treatment of syphilis among antenatal clients Voluntary counseling and testing for clients suspected to have HIV

example, 69 percent of facilities claim to offer STI management services and 49 percent HIV management services. Findings from case studies suggest that clinic- based programs in the region are adopting integration strategies that seek to include four major service components.

Situation Analysis studies in five countries found that although many MCH/FP facilities were offering STI and HIV/AIDS services, few clients were actually receiving these services. In Ghana, Zambia and Zimbabwe, clinics were found, on average, to provide STI services to one client per day and HIV/ AIDS services to one client per month, although huge variations were found. Moreover, fewer than half of one percent of family planning and $\mathrm{MCH}$ clients interviewed reported having received an STI or HIV service during their visit. Given the levels of infection indicated above, there would appear to be much scope for greater utilization of these services. 


\section{Are MCHIFP programs and facilities prepared to provide STI andlor HIVIAIDS services?}

If clinics are claiming to offer integrated services, are they ready and able to do so? One of the justifications for service integration is that the basic physical environment, equipment, supplies and IEC materials required to provide STI and HIV/AIDS services are similar to those required for $\mathrm{MCH}$ / FP services, and that $\mathrm{MCH} / \mathrm{FP}$ clinics already have most of these in place. However, Situation Analysis studies and case studies indicate that:

- Although wall posters with STI and HIV/AIDS messages were available at more than two-thirds of the health facilities in five countries, other materials essential for individual education and counseling (flipcharts and brochures) were rarely available. Also group health talks - a useful strategy for communicating health information to clients in busy clinics and populations with low literacy rates - were rarely given at the MCH/FP clinics.

- Fewer than half of the facilities in the programs studied had all four basic items of equipment and supplies required to perform a pelvic examination (directable source of light, at least one speculum, gloves and antiseptic lotion) - an essential step in assessing clients for STIs.

- A significant number of MCH/FP clinics do not have available the first line drugs recommended in their country guidelines for treating STIs. As a result, service providers often have to use alternative medication that may not be as effective in treating the STIs. Availability of drugs at the health facilities is influenced by both the availability of resources to purchase the drugs, and the presence of good logistics to ensure appropriate distribution.

- Most programs have revised their family planning guidelines and service standards to include STI and HIV/AIDS services and other reproductive health issues. However these documents are often not available at health facilities, and most service providers are unaware of their existence and/or the revisions.

Readiness to facilities to communicate messages on STIs and HIV/AIDS

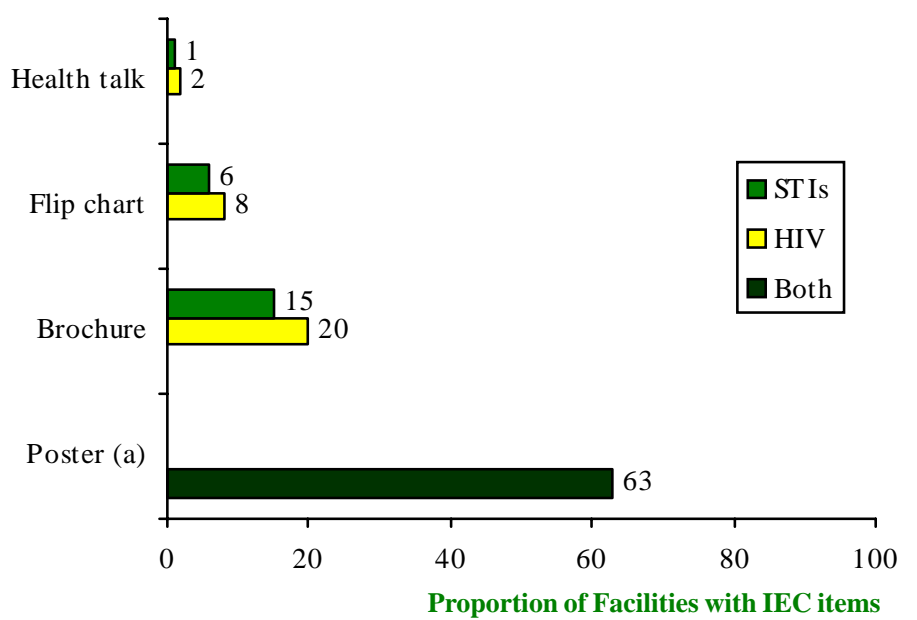

(a) no distinction was made between posters describing STIs and HIWAIDS when the data were collected 
None of the programs had undertaken revisions of their forms for collecting service statistics (for example client record cards, daily registers and service statistics summary forms) to cater for the additional information required in the management of STIs and HIV/AIDS. The absence of checklists, client record forms and reporting forms that reflect and support an integrated rather than specialized approach to interacting with the client has been blamed by providers themselves as Contributing towards their inability to implement a fully integrated approach.

\section{Are service providers in MCHIFP clinics prepared to provide STI and HIVIAIDS services?}

In addition, staff providing MCH/FP services are thought to already have most of the basic skills required for offering an integrated service, and are assumed to be willing and able to provide information and services for STI and HIV/ AIDS routinely. However:

- The majority of service providers in $\mathrm{MCH} / \mathrm{FP}$ clinics have not attended a post- basic or refresher course on STI and HIV/AIDS management. Basic training of service providers rarely includes STI and HIV/AIDS management, and most providers were trained many years ago. Moreover, the skills required for managing STIs and HIV/AIDS change rapidly, and so there is an urgent need for in-service training programs for providers and to establish systems that facilitate more frequent refresher and up-date courses.

STI and HIV risk assessment involves asking clients questions about their sexual behavior, that of their partners and other personal behaviors. Although up to two-fifths of service providers feel comfortable asking clients about these issues, one-fifth do not feel at all comfortable. Training and appropriate supervision to address these concerns will be required.

- Service providers often cite heavy client loads and a lack of time as the major hindrance to the provision of good quality and integrated services. A time notion study carried out for one family planning program revealed that staff spent up to one half of their official working time on tea/ lunch breaks and non- work related activities. Moreover, most MCHIFP clients are served in the morning only, with the clinics being underutilized in the afternoons.

- The study also showed that risk assessment and counseling for STIs and HIV \AIDS did not

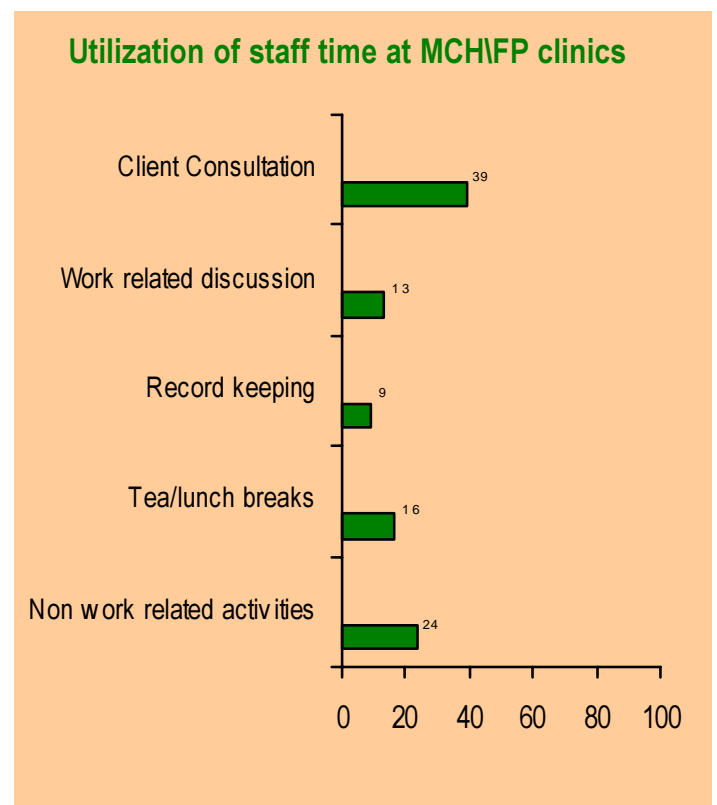

Proportion of Staff Time

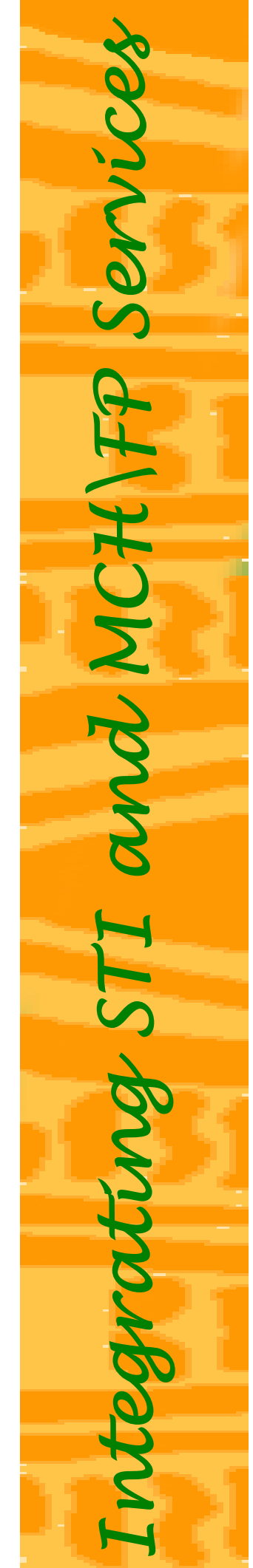


substantially increase the duration of consultations with new family

planning clients, repeat clients attending for their annual check-up, or clients using a method but having a problem. Consequently, time may not be a constraint to adding STI services to existing MCH/FP programs. What may be required is a re-organization of how staff utilizes their time.

\section{What quality of STI and HIV information and services are MCHIFP clients actually receiving?}

STI and HIV risk assessment; history taking and pelvic examination are rarely and inconsistently undertaken for $\mathrm{MCH} / \mathrm{FP}$ clients. However, the proportion of clients for whom these procedures are undertaken are higher for those programs where service providers have attended a post-basic and/ or refresher course in the management of STIs. Thus a concerted effort to improve integration does appear to have some effect, but more attention is needed to ensure that these procedures are routinely undertaken.

Proportion of new family planning clients asked risk assessment questions

$\begin{array}{llllll}\text { Proportion of new family planning clients asked risk assessment questions } \\ \text { Country } & \begin{array}{l}\text { Marital } \\ \text { status }\end{array} & \begin{array}{l}\text { Number of } \\ \text { new partners } \\ \text { in last year }\end{array} & \begin{array}{l}\text { Concerns } \\ \text { about } \\ \text { STls }\end{array} & \begin{array}{c}\text { Sexual } \\ \text { relations }\end{array} & \text { History } \\ \text { of STI }\end{array}$

$\mathrm{MCH} / \mathrm{FP}$ clients are rarely informed about STIs and HIV/AIDS during clinic consultations. In the five Situation Analysis studies, the proportion of new family planning clients with whom STls were discussed range from 40 percent in Zambia to 12 percent in Kenya, and the proportion with whom HIV/AIDS was discussed ranged fro 21 percent in Botswana to two percent in Zimbabwe. For those who were informed, the emphasis was on condom use, but symptoms, signs, risk factors, complications and modes of transmission of STIs and HIV infection were rarely discussed.

Although the majority of new family planning clients receiving services at $\mathrm{MCH} / \mathrm{FP}$ clinics are informed about the role of condoms in preventing pregnancies, few are given information about its role in preventing STIs and HIV/AIDS. Those who received a "dual protection' message (i.e. that a condom can protect against both pregnancy and infection) ranged from four percent in Zimbabwe to 31 percent in Botswana. 
Proportion of new family planning clients informed about condom use for pregnancy or STD prevention

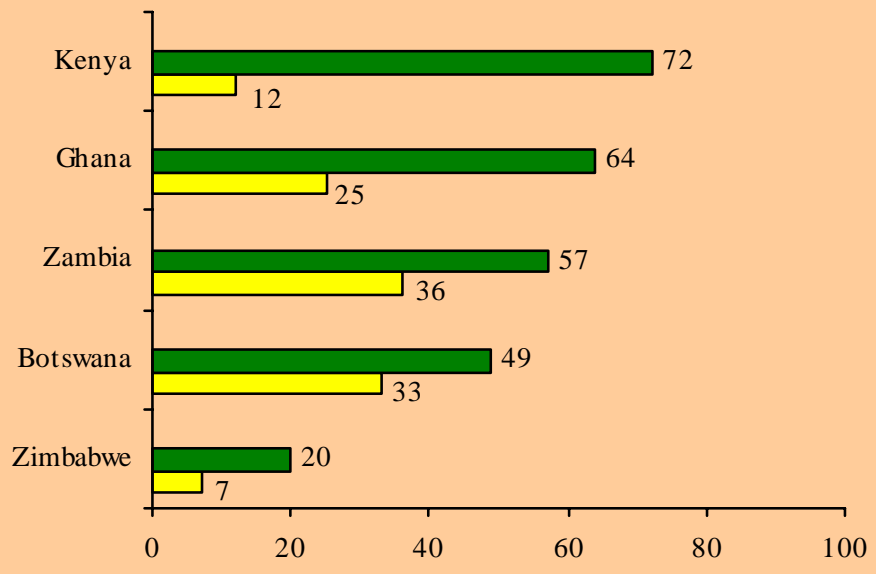

\section{Are partners of clients treated for STIs at MCHI FP clinics also treated?}

Partner notification and treatment is an essential component of STI management to prevent re-infection. However, data from two programs show that less than one-third of the sexual partners of family planning clients treated for STIs come for treatment, even when steps are taken to encourage them to do so. However, the case studies show that staff rarely informs clients treated for ST[s about the importance and need to get their partners treated. Partner notification and treatment is also complicated by the use of syndromic management of STIs in women. Most women diagnosed syndromically as having an abnormal vaginal discharge do not actually have a sexually transmitted infection (although they may have a naturally occurring infection). Therefore, great care needs to be taken in handling cases where it is not completely clear whether the infection was acquired through sexual transmission or not. Unfortunately, the use of syndromes (such as vaginal discharge) for the identification and management of reproductive tract infections does not make such a distinction.

\section{Are antenatal clients routinely tested and treated for syphilis at clinics?}

As noted above, one particular STI, syphilis, has been given special attention because of its impact on the health and survival of pregnant women and their babies. Consequently, syphilis testing and treatment for pregnant women is mandated in almost all countries because of its proven cost-effectiveness. Data collected from two programs in Kenya indicate, however, that between 27 and 52 percent of antenatal clients are being tested. Even when testing is done, not all women return for the results and treatment - in one program, of the 31 women tested and proving positive, only 18 returned for treatment and an even smaller number of their contacts get treated. Use of procedures that require clients to make more than one visit to the clinic or that include referral to another clinic, and the costs clients have to pay for the test are some of the reasons given for the poor performance of this intervention. 


\section{What are clients' perceptions about integrating? STI, HIVIAIDS and MCHIFP services?}

The majority of $\mathrm{MCH} / \mathrm{FP}$ clients indicated that they are comfortable with being asked questions about their sexual behavior and that of their partners. Moreover, when clients participating in a study that involved detailed risk assessment, history taking, a pelvic examination and laboratory testing, were asked to name what they liked most about their consultation, 70 percent named pelvic examinations and having a laboratory

Clients cite poor staff attitudes, stigmatization associated with STIs, fear rejection, poor confidentiality and the cost of obtaining services as the major reasons for not utilizing MCHIFP facilities for STI information and services

test. The clients that these

were helpful determining their health status.

These findings suggest that, contrary to popular perceptions that clients do not like being asked about their sexual behavior and/or receiving intrusive pelvic examinations, the majority of $\mathrm{MCH} / \mathrm{FP}$ clients do appreciate these procedures and would welcome a more comprehensive reproductive health consultation.

\section{What role can Community Based Distributors Play in the provision of STI and HIVIAIDS information and services?}

Many CBD programs in the region are reviewing the scopes of work for their agents, to expand their role beyond family planning to include other reproductive health services, especially education, counseling and referral for STI and HIV/ AIDS services. Although most CBDs are knowledgeable about family planning, their knowledge of ST[S and HIV/AIDS is relatively poor. For example in two programs, many CBDs were found to have poor knowledge of most of the common symptoms of STIs, and in many cases their level of knowledge was not significantly different from that of the clients they served.

CBD agents are usually respected and trusted members of the communities they serve, and may be related to or friends with many of their clients. Some CBD agents saw this as a handicap to discussing STIs, and especially when an infection is suspected, with their clients. This factor needs to be taken into account when reviewing their responsibilities to include STI management beyond education.

CBD agents appear to have the potential to reach many people with detailed information about STI prevention and management, and particularly the higher risk groups of men and adolescents. However, the feasibility, acceptability and effectiveness of doing so is not known and so furthr research is essential to guide CBD programs seeking an expanded role 


\section{How effective are existing procedures for detecting and managing STIs in MCHIFP clients?}

Two OR studies supported findings from other studies in the region that many women with laboratory evidence of an RTI did not have any symptoms of abnormal vaginal discharge when asked their history and/or during clinical examination. The study in Kenya found that 49 percent of a symptomatic family planning clients and 56 percent of a symptomatic antenatal clients had laboratory evidence of an RTI. The Zimbabwe study found that 29 percent of a symptomatic family planning clients had a positive lab test for an RTI. For these a symptomatic women, the syndromic approach cannot be used to detect and manage their infection.

These studies also showed that many women, who complained of an abnormal vaginal discharge and/or were found to have one on examination, did not have any infection on laboratory testing. In Kenya for example, 33 percent of the antenatal clients and 46 percent of the family planning clients with a vaginal discharge symptom and/or clinically determined sign did not have laboratory evidence of an infection. Among family planning clients in Zimbabwe, the proportion was even higher at 64 percent. Thus diagnosing and treating these women according to their symptoms has led to over treatment and represents wasted resources.

Observations of client-provider interactions showed that even when clients have symptoms and/or signs suggestive of an infection (as described by the national syndromic management algorithms) clinic staff do not always make a diagnosis as described in these algorithms. This was so, despite the refresher training in syndromic management the staff received at the beginning of the two OR studies. Consequently, if the syndromic approach is going to be used, great care must be taken to make sure that the training is effective and that supervision maintains compliance with protocol guidelines.

Many programs in the region (e.g. Kenya) recommend that women presenting with vaginal discharge and/or found to have vaginal discharge on examination should be treated for vaginitis (e.g. Trichomoniasis, Candida or Bacterial Vaginosis) first. They are requested to then come back after seven days to assess clinical progress, and if no improvements are found the client is then treated for cervicitis. In the Kenya study, however, 48 percent of family planning clients and 38 percent of antenatal clients with a vaginal discharge were found not to have vaginitis. Moreover, among those women who did have vaginitis, 88 percent of family planning clients and 67 percent of antenatal clients did not have the vaginal discharge symptom. Using the presence of vaginal discharge symptom and/or sign as a predictor of vaginitis, therefore, leads not only to many women who need to be treated being missed, but also to over-treating many women who do not have such infections. 
In addition, the studies found that fewer than one-half of women came back for the follow-up visit, regardless of their infection status. Therefore, many women requiring a change in their treatment will be missed when this approach is used.

Given this problem with follow-up and the seriousness of cervical infections, other programs in the region (including Zimbabwe), recommend that all women presenting with and/or found to have a vaginal discharge should be treated for gonorrhea and chiamydia, that is, for cervicitis. The two studies show, however, that this leads to many women without a cervical infection being prescribed antibiotics. For example, fewer than 15 percent of clients with vaginal discharge symptom and/or sign were found to have laboratory evidence of cervicitis. Moreover, many women with a cervical infection did not have vaginal discharge symptom and/or sign (88 percent and 61 percent for antenatal and family planning clients respectively in Kenya, and 40 percent in Zimbabwe). As with vaginitis, therefore, the presence of vaginal discharge symptom and/or sign as a predictor leads to both over and under treatment.

The syndromic approach was developed for use when clients visit clinics explicitly seeking STI treatment, rather than for screening clients attending $\mathrm{MCH} / \mathrm{FP}$ clinics. The two OR studies show that the syndromes for vaginal discharge and lower abdominal pain have statistically strong sensitivity for detecting cervical infections among clients who actively seek STI services, but have very poor specificity and positive predictive values. This means, therefore, that the overall effectiveness of the syndromic approach is poor, even for those clients who are actively seeking treatment for a suspected STI.

\section{Effectiveness of symptoms andlor signs in predicting RTls among clients seeking STI services from a family planning clinic}

\begin{tabular}{|l|l|c|c|c|}
\hline $\begin{array}{l}\text { CLINICAL } \\
\text { INFORMATION }\end{array}$ & \multicolumn{1}{|c|}{$\begin{array}{c}\text { TYPE OF } \\
\text { RTI }\end{array}$} & \multicolumn{3}{|c|}{ EFFECTIVENESS IN PREDICTING RTIS } \\
\hline & Sensitivity & Specificity & $\begin{array}{c}\text { Positive } \\
\text { Predictive } \\
\text { value }\end{array}$ \\
\hline $\begin{array}{l}\text { Vaginal discharge } \\
\text { symptom }\end{array}$ & $\begin{array}{l}\text { Cervicitis } \\
\text { Vaginitis }\end{array}$ & 7269 & 4144 & 934 \\
\hline $\begin{array}{l}\text { Vaginal discharge } \\
\text { sign }\end{array}$ & $\begin{array}{l}\text { Cervicitis } \\
\text { Vaginitis }\end{array}$ & 6260 & 5560 & 1038 \\
\hline $\begin{array}{l}\text { Vaginal discharge } \\
\text { symptom and sign }\end{array}$ & $\begin{array}{l}\text { Cervicitis } \\
\text { Vaginitis }\end{array}$ & 5540 & 6670 & 1141 \\
\hline $\begin{array}{l}\text { Lower abdominal } \\
\text { pain }\end{array}$ & $\begin{array}{l}\text { Cervicitis } \\
\text { Vaginitis }\end{array}$ & 8668 & 2622 & 827 \\
\hline
\end{tabular}


Three major factors appear to contribute to the ineffectiveness of syndromic management.

First, most women have poor knowledge of STI symptoms, and many are a symptomatic and/ or have no clinical signs even when they have an infection. Research is urgently needed to find out whether improving women's knowledge and ability to identify symptoms will improve their health-seeking behavior, thereby increasing the effectiveness of the syndromic approach.

Second, as seen above, the symptoms and/or signs used in the existing algorithms for syndromic management have been shown not to be effective in predicting whether or not a women has an infection, due to their poor sensitivity, specificity and positive predictive values. The Africa OR/TA Project 11 undertook studies in Kenya and Zimbabwe to determine whether adding risk assessment to the client consultation would improve the effectiveness of detecting and managing STIs

(See below).

Third, staff were found to not always follow the service delivery guidelines for screening and managing $\mathrm{MCH} / \mathrm{FP}$ clients for possible infections, even when there is sufficient information from history-taking and clinical examination to suggest the possibility of an infection. The studies in Kenya and Zimbabwe also tested whether using a checklist would improve the provider's capacity to correctly implement the standard procedures for an integrated approach (see below).

\section{Can the effectiveness of the syndromic approach be improved by adding risk assessment?}

Adding risk assessment has been proposed as a means for improving the effectiveness of the syndromic approach for detecting infections among $\mathrm{MCH} / \mathrm{FP}$ clients who present without symptoms. A risk assessment is relatively simple to undertake - it requires the provider to ask the women a number of questions about her and her partners' behavior, the answers to which may indicate that she is at increased risk of contracting an STI. The factors most commonly included are: multiple sex partners; current or past STIs; perception of STI risk; and staying away from partner.

For these two OR studies, the objective was to find out whether it was possible to establish a small number of questions that would significantly improve the ability of providers to detect and manage MCH/FP clients with STIs. To do this, a set of 23 risk factors was identified from the literature and through expert knowledge of the local situation. Researchers interviewed clients after their consultation to obtain information about each of these factors. These data were then analyzed in relation to whether or not the woman was actually infected, as indicated by a laboratory test. From this analysis, a reduced set of six key risk factors was identified as being those most likely to predict an infection. The findings were as follows: 
- The factors that are usually considered to be indicative of increased risk were uncommon among women attending $\mathrm{MCH} / \mathrm{FP}$ clinics in Kenya and Zimbabwe.

- Strengthening the algorithm by combining selected information from the client's medical history, a clinical examination and risk assessment leads to a small improvement in effectiveness of the algorithms to correctly identify clients with a cervical infection (the positive predictive value). There is also a small improvement for identifying those without a cervical infection (the specificity). However, the ability of the algorithm to identify cervical infections in a pool of clients known to be positive (its sensitivity) remained low.

\section{Does the use of a standardized checklist improve the quality of an integrated approach?}

A major reason identified by staff for their not systematically assessing and counseling MCH/FP clients on STI/HIV was the lack of a checklist and record keeping system that would facilitate an integrated consultation. Drawing from this finding, the studies in Kenya and Zimbabwe developed and introduced an integrated checklist to be used by clinic staff during history taking, clinical examination and STVHIV risk assessment for all $\mathrm{MCH} / \mathrm{FP}$ clients. The checklist included 23 STI/HIV risk factor items and 13 counseling and information items that a provider should discuss with a client, and allowed space for the information obtained to be recorded. The results of this study showed that:

- Although staff found it difficult and time consuming at first to use the checklist, they gradually accepted it as part of their routine procedure for collecting information from and giving information to their clients. With time, the staff reported that the checklist enabled them to spend the time with clients more efficiently, and were thus able to build a better rapport, collect more detailed information required for proper diagnosis and management, and to counsel their clients in a more systematic manner.

- Clients felt that service providers were now spending more time with them and providing a more thorough examination, resulting in a better understanding of their problems.

- Both the staff and clients felt comfortable with the risk assessment questions. One reason given by the clients was that the questions on sexual behavior gave them the opportunity to think about and re-examine their own lives. 
Following the introduction of the checklist, the vast majority of clients (7899\%) were now receiving systematic counseling on key STIs and HIV/AIDS topics. The quality of information given on family planning also improved significantly.

\section{How has operations research strengthened integration of STIIHIV and family planning services?}

Kenya: The two case studies undertaken in Kenya helped to identify weaknesses in the strategies used to integrate STI and family planning services. The strategy had focused on training staff in syndromic management and providing STI- dedicated drug kits. The research found that the training did not cover the essential skills required by the providers, the MIS had not been revised to facilitate recording and reporting of information needed for providing and monitoring integrated programs, prescribing policies had not been reviewed to allow the trained nurses to prescribe STI drugs, indicators of program performance had not been reviewed to include STI and HIV services and there were no job aides to assist the providers providing services using an integrated approach. The two programs have already reviewed their training curricula and MIS to cover those areas found to be deficient by the studies, and have also reviewed their cost recovery strategies.

Results from these studies contributed to the inclusion of a section on the integration of STI/HIV/AIDS control into the MCH/FP program within the revised

National Reproductive Health/Family Planning Policy Guidelines and Standards for Service Providers. The findings also led to national debate on the prescribing

Policies that currently do not allow nurses to prescribe STI drugs. The matter was taken up by parliament and changes in legislation to allow the nurse to prescribe have been approved.

Uganda: Results from the case study helped the program in identifying its requirements and were used to inform and solicit for support from donors. The program was able to get the $\mathrm{MOH}$ to provide KEPI fridges to some of their clinics; they were able to get more equipment and drugs from donors using the study findings to back up their requests. The program reviewed its training curriculum to cover areas in which the study found the staff to be deficient. Client flow and privacy were found to be a problem in many of the facilities and structural adjustments were required. The program used these results to convince the communities to undertake the necessary structural adjustments and to put billboards at the clinics to inform clients of the availability of STI/ HIV services.

Botswana: The $\mathrm{MCH} / \mathrm{FP}$ unit has utilized the results to more accurately define areas in their program that need attention. For example, the trainers from the Botswana Population Assistance (BOTSPA) Project used the results to revise the training curriculum for nurses in providing STI/HIV services in 
$\mathrm{MCH} / \mathrm{FP}$ clinics to put more emphasis on those skills found to be deficient.

The MCH/FP unit also revised their client record forms to facilitate the providers in obtaining, recording and reporting information essential for providing STI/HIV and family planning services using an integrated approach. Study results have been used in training workshops for supervisors in the District Health Management Teams and the development of supervision checklists. The MCH/FP unit has used information from the studies to develop indicators to monitor the performance of their program and many of these indicators have been incorporated in the Ministry of Health Information System for use at a national level.

Zimbabwe: A new training module specifically addressing the provision of $\mathrm{MCH} / \mathrm{FP}$ and STI services using an integrated approach was developed as part of the study activities and will form part of the national training curriculum. This new module has also been used by WHO to train staff in other programs with Sub-Saharan Africa. The study also helped to identify weaknesses in the current treatment algorithms given the disease patterns. Information from the studies is being used by the national STI management committee to review the STI management guidelines in view of the study findings. The study findings are being used by the ZNFPC to revise their MIS to facilitate the provision of STI and family planning services using an integrated approach.

\section{Resources available from the Africa ORITA Project 11 on Integration of STIIHIV and MCHIFP Information and Services}

Askew, lan. 1998. Designing a process for developing guidelines and standards for promoting dual protection', paper presented at the Regional Conference on Guidelines and Standards for Reproductive Health, Harare, Zimbabwe, 8-12 June.

Askew, lan and Baker Ndugga Maggwa. 1996. Operations research on the integration of STVAIDS services into MCH/FP programs in east and southern Africa: Findings from Situation Analyses and case studies in selected countries. Paper presented at a workshop on "The interface between family planning and HIV/STD prevention,' co-sponsored by IUSSP, WHO, IWellcome Trust and The African Population Policy Research Centre, Nairobi, Kenya, 2-4 October.

Askew lan, Baker Ndugga Maggwa, and Lenni Kangas. 1998. 'Integrating STI and HIV/AIDS services into MCH/FP programs in East and Southern Africa', paper presented at the Annual Meeting of the Population Association of America, Chicago, Illinois, USA, April 2-4.

Askew lan, Fassihian Goli and Maggwa Baker Ndugga. 1998. 'Integrating STI and HIV/AIDS services with family planning and $\mathrm{MCH}$ services at clinics in sub-Saharan Africa'. in Clinic-based Family Planning Services in sub-Saharan Africa: Findings from Situation Analysis Studies. Africa OR/TA Project 11, Population Council, New York, USA.

Baakile, Benjamin, Baker Ndugga Maggwa, Lucy Maribe, and Robert A. Miller. 1996. A Situation Analysis of the maternal and child health/family planning (MCH/FP) program inBotswana.

Prepared by the Africa OR/TA Project 11 in cooperation with the Ministry of Health MCH/FP Unit, Family Health Division. Gaborone, Botswana, July.

Chege Jane and Askew lan, 1997. 'An Assessment of Comrnunity-Based Family Planning Programmes in Kenya' Africa ORITA Project 11, Population Council, Nairobi, Kenya.

Dube Hazel, Marangwanda Carolyn and Ndhiovu Lewis 1998 'An Assessment of the Zimbabwe Family Planning Programme: Results from the 1996 Situation Analysis Study' Africa ORITA

Project 11, Population Council, Nairobi, Kenya. 
62 Ghana Statistical Services. 1997. 'Second Round Situation Analysis Study of Family Planning Service Delivery Points in Ghana 1997’ Africa OR/TA Project 11, Population Council, Nairobi, Kenya.

Kariba, James, Bedan Kariuki and Baker Ndugga Maggwa. 1997. Integration of STI and HIV/ AIDS with MCH-FP Services: A case study of the Nakuru Municipal Council's Project on Strengthening STD/AIDS Control. Nakuru Municipal Council and the Africa OR/TA Project 11, Nairobi, Kenya, April.

Maggwa, Baker Ndugga. 1998. 'A rapid assessment tool for evaluating the quality of the integrated $\mathrm{MCH} / \mathrm{FP}$ and STD/HIV programs in Botswana', paper presented at the 126th Annual Meeting of the American Public Health Association, Washington, D.C., November 15-19.

Maggwa, Baker Ndugga. 1998. The integration of STI/HIV services with MCH/FP services. Paper presented at the Regional Conference on Guidelines and Standards for Reproductive Health, Harare, Zimbabwe, 8-12 June.

Maggwa, Baker Ndugga and lan Askew. 1997. Integrating STI/HIV management strategies into existing MCH/FP programs: Lessons from case studies in East and Southern Africa. Population Council, Nairobi, Kenya, July.

Maggwa, Baker Ndugga 1996. Sexually transmitted infections, family planning, and maternal- child health: integrating services in sub-Saharan Africa. Population Briefs 2(4):4.

Maggwa, Baker Ndugga and lan Askew. 1997. Integrating STI/HIV management strategies into existing MCH/FP programs: Lessons from case studies in East and Southern Africa. Paper presented at workshop on 'Improved Reproductive Health: International Shared Experiences' by the Population Council, Bogor-West Java, Indonesia 4-5 December.

Maggwa, Baker Ndugga and lan Askew. 1997. 'Integrating STI/HIV management strategies into existing MCH/FP programs: Lessons from case studies in East and Southern Africa'. Paper presented at the 125th annual meeting of the American Public Health Association, Indianapolis, Indiana, 9-13 November.

Maggwa, Baker Ndugga, Naomi Rutenberg and lan Askew. 1997. "A challenge to integrating STI/HIV management strategies into existing $\mathrm{MCH} / \mathrm{FP}$ programs in East and Southern Africa: Talking about sex and sexually transmitted diseases'. Paper presented at the 125th annual meeting of the American Public Health Association, Indianapolis, Indiana, 9-13 November.

Maggwa, Baker Ndugga. 1997. 'STD services and comprehensive primary health care: The practical implications'. Paper presented at the Forum on Establishing Appropriate Services for the Management and Prevention of STDS, Department of Health, Johannesburg, South Africa, 25-26 September.

Maggwa, Baker Ndugga and Placide Tapsoba. 1996. Collecting information on other reproductive health services through the Situation Analysis approach. Paper presented at a workshop on "Strengthening the Utilization of Situation Analysis for Planning, Managing and Evaluating Reproductive Health Services,' Population Council, Nairobi, Kenya, 29-31 May.

Maggwa, Baker Ndugga, lan Askew, and Andy Fisher. 1995. 'Integration of STI and HIV/AIDS services with $\mathrm{MCH}-\mathrm{FP}$ services: Experiences from four countries in sub-Saharan Africa'. Paper presented at the annual meeting of the American Public Health Association, San Diego, CA, 29 October-2 November.

Baker Ndugga Maggwa, lan Askew, Carolyn Marangwanda, Sikhozile Simba and Hazel Dube. 1999. 'Assessing the potential demand for and effectiveness of integrating STI/HIV management services with Zimbabwe National Family Planning Council's clinic-based family planning services.' Africa ORITA Project 11, Population Council, Nairobi, Kenya.

Maribe, Lucy and Scott Stewart. 1995. 'Botswana's national program of integrated services - what are the costs: A case study'. Paper presented at the annual meeting of the American Public Health Association, San Diego, CA, 29 October-2 November.

Maribe, Lucy Sjo, Baker Ndugga Maggwa, lan Askew and Kate Miller. 1997. Using a rapid assessment approach to evaluate the quality of care in an integrated program: The experience of the Family Health Division, Minis" of Health, Botswana. Population Council, Nairobi, Kenya, November.

Miller, Robert, Karen Stein, Kate Miller, Lewis Ndhlovu, Baker Ndugga Maggwa, DiouratiL6 Sanogo and Emmy Kondo. 1996. Measuring reproductive health care after Cairo: Findings from four Situation Analysis studies in Africa. African journal of Fertility, Sexuality and Reproductive Health 1(2):92-100.

Mukaire, Joy, Florence Kalikwani, Baker Ndugga Maggwa and Wilson Kisubi. 1997.

Integration of STI and HIV/AIDS services with MCH-FP services: A case study of the Busoga Diocese Family Life Education Program, Uganda, Busoga Diocese Family Life Education Program, the Africa OR/TA Project 11 and Pathfinder International, Nairobi, Kenya, January.

Solo J., Maggwa BN., Kariba JW., Karuiki BK and Maitha G. 1999. 'Improving the management of STis among MCH/FP clients at the Nakuru Municipal Council Health Clinics' Africa OR/TA Project 11, Population Council, Nairobi, Kenya.

Twahir, Amina, Baker Ndugga Maggwa and lan Askew. 1996. Integration of STI and HIV/AIDS services with $\mathrm{MCH} / \mathrm{FP}$ services: a case study of the Mkomani Clinic Society in Mombasa, Kenya. Mkomani Clinic Society and the Africa OR/TA Project 11, Nairobi, Kenya, April. 
Twahir, Amina and Baker Ndugga Maggwa. 1995. 'Mkomani Clinics: Integration of MCH/FP with STD/H IV services - what are the costs: A case study', Paper presented at the annual meeting of the American Public Health Association, San Diego, CA, 29 October-2 November.

\section{Africa ORITA Project II}

These studies wee supported by the Popuolation Council;s Africa Operations Research and Technical Assistance Project II. The Africa ORITA Project II is funded by the US Agency for International Development (A.I.D.), Office of Population Contract No. CCC-3030-C-00-300800, Strategies for improving Family Planning Service Delivery.

For further information contact any of the following Population Council Offices:

Nairobi

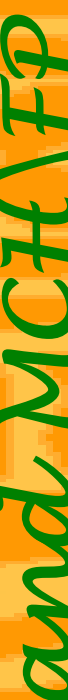<smiles>C1CC2C(C1)C1CC2C2CCCC21</smiles>

Dakar

Dakar

New York

P.O. Box 17643 Tel: $\mathbf{7 1 3 4 8 0 - 3}$

Fax: 713479

Email: mwanjiru@ popcouncil.orke

PB 21027

Tel: 221-8-241993

Fax: 241998

Dakar, Senegal

Ouagadougou

01 BP 6250

Tel: 226-361607

Fax: 361625

Ouagadougou

Burkina Faso

One Dag hammarskjold Plaza

NY, NY 10017. USA

Tel: 212-3390500

Fax: 212-7556052

New York

Washington

4301 Connecticut Avenue

NW Suite 280

Washington DC 20008

USA

Tel : 1-202-2379400

Fax : 1-202-2378410 